\title{
An Empirical Study on Credit Construction of College Students in Chengdu
}

\author{
Xiao Li, Kai Xu, Siyu Wu, Tingting Xie, Hongwei Ruan, Man Zheng \\ School of Business, Chengdu University \\ Chengdu, China \\ 363164311@qq.com

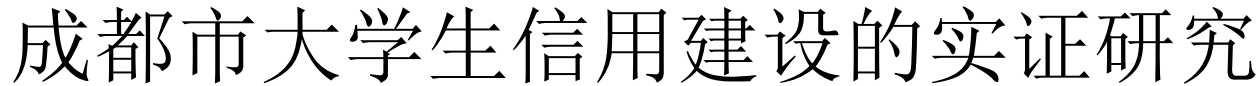 \\ 李潚, 徐凯, 伍思雨, 谢婷婷, 阮鸿伟, 郑曼 \\ 成都大学商学院 \\ 成都 610106, 中国 \\ 363164311@qq.com
}

\begin{abstract}
Firstly, this paper divides the credit of college students into four dimensions: credit of honesty, credit of employment, credit of credit and credit of consumption. Starting from the current situation of credit construction of college students in Chengdu, this paper reveals the problems and deficiencies in the construction of college students' credit. Secondly, through a questionnaire survey, using the method of quantitative analysis, the paper establishes a credit evaluation model for college students, analyzes the influencing factors on the credit construction of college students, and puts forward countermeasures to improve the credit level of college students, promote the integration of the credit construction of college students with the social credit system, and promote the perfection of Chengdu's credit system.
\end{abstract}

Key words-College students' credit, Credit dimension, Credit construction

摘要一本文首先将大学生信用划分为诚信信用、就业信 用、信贷信用、消费信用四个维度, 从成都市大学生信用建 设现状出发, 揭示大学生信用在建设中存在的问题和不足。 其次, 通过问卷调查, 利用计量分析的方法, 建立大学生信 用评价模型, 分析对大学生信用建设的影响因素, 提出对策 以提升大学生信用水平, 促进大学生信用建设与社会信用体 系的接轨，推动成都市大学生信用体系的完善。

关键词：大学生信用，信用维度，信用建设

\section{I. 引言}

2019 年国务院政府工作报告再次强调 “健全社会信 用体系” 的重要性，指出各项经济工作的完成须以完善 的社会信用体系为保障。大学生作为最具代表性的青年 群体, 其道德品质、信用状况对社会经济发展影响重 大, 在全面加强社会信用建设的背景下, 大学生的信用

通信作者: 徐凯, 副教授, 邮箱:

363164311@qq.com，联系手机：18109049862

基金项目：成都市科技局软科学项目(2016-RK00-

00010-ZF); 四川省教育厅人文社会科学重点研究基地 四川景观与游憩研究中心科研项目(JGYQ2018004); 四 川省社会科学重点研究基地四川县域经济发展研究中心 项目(xy2018016); 成都大学创新训练计划孵化培育项 目(CDU-CX-2019336); 四川省大学生创新创业训练计 划项目(S201911079083)。
建设逐渐受到社会各界的关注。目前国内有关大学生信 用建设的理论研究尚未成熟，在政府管理保障制度的欠 缺、信用教育体系不完善、个人信用征信体系不健全等 因素的共同作用下, 我国大学生信用建设的路途任重而 道远。

根据现代信用建设主体的不同, 可将信用划分为政 府信用、银行信用、企业信用、个人信用四种类型，大 学生信用属于个人信用的分支。在大学生信用维度的划 分上, 刘姿含 (2014) 将大学生信用维度分为学习信 用、工作信用、择业信用、自然信用、能力信用、经济 信用、生活信用七个维度[1]。王达山（2016）指出, 在互联网技术快速发展的背景下，不仅要重视大学生诚 信信用和学习信用, 学生互联网经济信用和网络社交信 用也不容忽视[2]。丁建福 (2007) 通过博弯论分析大 学生信用建设的影响机制, 通过比较有无政府机制和第 三方市场化机制参与大学生信用建设的状况, 得出政府 体制管理对学生信用建设具有显著影响, 市场征信的参 与使得信用体系更加完善 [3]。蔵学涁等 (2019) 指出 大学生信用评价体系建立, 需要在政府主导的征信体系 基础上, 融入互联网征信体系, 加强政府征信、高校大 学生信用体系和用人单位的信用网络系统的联系, 促进 大学生信用体系信息的完善[4]。

基于成都市大学生信用建设的实证分析, 利于补充 大学生信用建设研究的理论, 对创造良好的信用环境、 促进大学生信用体系与社会信用体系的接轨具有现实意 义。本文从成都市大学生信用建设中的不足出发, 以成 都市高校大学生为调查对象, 通过问卷调查获得大学生 相关信用数据, 根据划分信用维度构建大学生信用评价 模型, 并运用多元回归方法对影响大学生信用水平的因 素进行验证分析, 得出结论。

\section{II. 大学生信用评价模型指标的信度检验}

\section{A. 大学生信用评价模型指标}

借鉴刘姿含（2014）大学生信用划分维度, 本文从 大学生学习信用、校园生活信用、消费信用、就业信用 四个层次构建大学生信用评价模型。学习信用类别包括 大学生考试违规、论文作业的抄袭状况、综合成绩排名 
和课堂纪律四个指标，校园生活信用类别包括图书归还 状况、学费住宿费缴纳状况、校园处分状况，消费信用 指标采用芝麻信用分进行评价, 就业信用类别采用履历 信息的真实状况进行评价。

\section{B. Cronbach 信度检验}

根据检验结果（参见表 1 ），可见 Cronbach $\alpha$ 信度 系数值 0.688 , 说明数据信度良好, 各指标的信度质量 可以接受。“学习成绩” 指标对应的 CITC 值小于 0.2 , 说明它与其他项的关系较弱, 需要对其进行剔除 进行信度检验。

表 1 大学生信用评价指标的 Cronbach 信度检验

\begin{tabular}{|c|c|c|c|}
\hline 名 称 & $\begin{array}{c}\text { 校正项总 } \\
\text { 计相关性 } \\
\text { (CITC) }\end{array}$ & $\begin{array}{l}\text { 项已删 } \\
\text { 除的 } \alpha \\
\text { 系数娒 }\end{array}$ & $\begin{array}{c}\text { Cronbac } \\
\text { ha 系 } \\
\text { 数姆 }\end{array}$ \\
\hline 考试违规情况 & 0.418 & 0.65 & \multirow{9}{*}{0.688} \\
\hline 综合学习成绩 & 0.032 & 0.75 & \\
\hline $\begin{array}{c}\text { 作业论文抄袭 } \\
\text { 状况 }\end{array}$ & 0.332 & 0.667 & \\
\hline $\begin{array}{c}\text { 上课缺勤、早 } \\
\text { 退情况 }\end{array}$ & 0.368 & 0.662 & \\
\hline 图书归还状况 & 0.481 & 0.637 & \\
\hline $\begin{array}{c}\text { 学费住宿费的 } \\
\text { 缴纳情况 }\end{array}$ & 0.763 & 0.614 & \\
\hline $\begin{array}{c}\text { 受学校处分情 } \\
\text { 况 }\end{array}$ & 0.633 & 0.632 & \\
\hline 芝麻信用分值 & 0.252 & 0.685 & \\
\hline $\begin{array}{c}\text { 简历与实际状 } \\
\text { 况相符 }\end{array}$ & 0.434 & 0.647 & \\
\hline
\end{tabular}

表 2 剔除综合学习指标后的 Cronbach 信度检验

\begin{tabular}{cccc}
\hline 名称 & $\begin{array}{c}\text { 校正项总 } \\
\text { 计相关性 } \\
\text { (CITC)姆 }\end{array}$ & $\begin{array}{l}\text { 项已删 } \\
\text { 除的 } \alpha \\
\text { 系数 }\end{array}$ & $\begin{array}{l}\text { Cronba } \\
\text { ch } \alpha \\
\text { 系数 }\end{array}$ \\
\hline $\begin{array}{c}\text { 考试违规情况 } \\
\text { 作业、论文时抄 } \\
\text { 袭状况 }\end{array}$ & 0.434 & 0.727 & \\
上课缺勤、早退 & 0.357 & 0.74 & \\
情况 & 0.431 & 0.731 & \\
图书归还状况 & 0.473 & 0.719 & 0.75 \\
学费住宿费的缴 & 0.752 & 0.691 & \\
纳情况 & & & \\
受学校处分情况 & 0.626 & 0.707 & \\
芝麻信用分值 & 0.269 & 0.76 & \\
简历与实际状况 & 0.476 & 0.718 & \\
相符 & & & \\
\hline
\end{tabular}

剔除相关指标 (参见表 2 ) , $\alpha$ 信度系数值为 $0.75>0.6$, 说明研究数据信度质量良好。剔除 “学习成 绩” 指标后, 评价模型的信度系数并未明显的上升, 同 时引起 “芝麻信用分值” 指标对应的 CITC 值低于
0.4 , 带来新的问题, 说明该指标不应被剔除处理。综 上所述, Cronbach $\alpha$ 信度检验结果说明数据信度质量 高, 考察大学生信用水平应综合学习信用、就业信用、 消费信用和校园生活信用各个维度进行评价, 全面真实 的反映学生信用状况。

III. 大学生信用评价问卷的一致性检验

依据划分的四个大学生信用维度, 学习信用、校园 生活信用、互联网消费信用、就业信用, 采用 1-5 分的 标度法进行打分, 构建判断矩阵。通常情况下 CR 值越 小, 则说明判断矩阵一致性越好, 一般情况下 $\mathrm{CR}$ 值小 于 0.1 , 说明判断矩阵满足一致性检验。根据 4 阶判断 矩阵计算得到 CI 值为 $0.000, \mathrm{RI}$ 值查表为 0.890 , 计算 得到 $C R$ 值为 $0.000<0.1$, （参见表 3 表 4) 说明判断矩 阵满足一致性检验, 计算所得权重具有一致性。综上所 述, 根据 HAP 层次分析法的结果, 表明学生信用评价 中学习信用指标、互联网消费信用指标、在校生活信用 指标在学生信用评价时较就业信用指标而言更影响更 大, 与实际情况相符合, 因此, 大学生信用评价体系应

表 3 AHP 层次分析表

\begin{tabular}{cc}
\hline 阶层 & RI 值 \\
\hline 3 & 0.58 \\
4 & 0.9 \\
5 & 1.12 \\
6 & 1.24 \\
7 & 1.32 \\
8 & 1.41 \\
9 & 1.45 \\
10 & 1.49 \\
11 & 1.52 \\
12 & 1.54 \\
13 & 1.56 \\
14 & 1.58 \\
15 & 1.59 \\
\hline
\end{tabular}

表 4 随机一致性 RI 检验

\begin{tabular}{ccccc}
\hline 所属维度 & $\begin{array}{c}\text { 特征向 } \\
\text { 量 }\end{array}$ & 权重值 & $\begin{array}{c}\text { 最大特 } \\
\text { 征值 }\end{array}$ & $\begin{array}{c}\text { CI } \\
\text { 值 }\end{array}$ \\
\hline $\begin{array}{c}\text { 就业信用 } \\
\begin{array}{c}\text { 校园生活 } \\
\text { 信用 }\end{array}\end{array} 0^{1.2}$ & $30.00 \%$ & 4 & 0 \\
互联网消 & 1.2 & $30.00 \%$ & & \\
费信用 & & & & \\
学习信用 & 1.2 & $30.00 \%$ & & \\
\hline
\end{tabular}


该侧重学生在校生活信用、学习信用、互联网消费信用 的考察，使学生信用水平得以真实反映。

\section{IV. 大学生信用水平影响因素的多元回归分析}

\section{A. 变量设定和模型建立}

本文依据四维大学生信用维度, 着重分析社会教育 因素、大学生个人因素对其信用水平的影响, 其中社会 教育因素进一步划分为年级、专业、学习成绩三因素, 个人因素为体现主体差异性, 选取了性别、户口、月生 活费作为变量。通过赋分法将定性指标进行量化, 以加 权得大学生个人信用水平值为数据进行回归分析。

根据影响机制分析，构建多元回归模型:

$Y=\alpha_{0}+\alpha_{1} D_{1 i}+\alpha_{2} D_{2 i}+\alpha_{3} D_{3 i}+\alpha_{4} D_{4 i}+\alpha_{5} D_{5 i}+\alpha_{6} D_{6 i}+\beta X_{i}+u$

其中, $Y$ 是因变量, $X_{i}$ 是解释变量, $D_{1 i}$ 表示性别的 虚拟变量, $D_{2 i}$ 表示年级的虚拟变量, $D_{3 i}$ 表示专业的虚

\section{B. 大学生信用建设影响因素的多元回归分析}

根据统计结果，对多元线性回归模型进行拟合优度 检验, $\mathrm{R}^{2}=0.191$, 模型（1）表明模型的拟合优度较 低, 方程解释能力较弱。 $\mathrm{F}$ 统计量的 $\mathrm{P}$ 值为 0.027907 , 小于 $10 \%$ 的置信水平, 拒绝原假设, 说明回归方程联合 显著, 即“性别”、“专业”、“年级”，“性别”、 户籍、“学习成绩”、“在校干部工作经历” 联合起来 对大学生信用水平有显著影响。在 $\alpha=10 \%$ 的水平下进 行 $\mathrm{t}$ 检验, “性别”、“年级”、“专业”、“户 口”、“月生活费”、“是否担任过学生干部” 各变量 的统计量对应 P 值均大于 0.1 , 说明各变量对大学生信 用水平不存在显著影响。由于部分大学生信用建设因素 对大学生信用水平影响不显著, 采用剔除变量法, 剔除 “性别”、“年级”、“户籍”、“在校干部工作经 历” 变量, 进行回归分析。在模型 (2) 中, “学习成 绩” 和 “月生活费” 对大学生信用水平有显著影响,

“专业” 对大学生信用水平的影响不显著, 因而进一步

表 5 多元回归分析结果一览表

\begin{tabular}{|c|c|c|c|c|c|}
\hline 变量名称 & & 变量定义 & 模型(1) & 模型(2) & 模型(3) \\
\hline 因变量 & $\begin{array}{l}\text { 大学生信用 } \\
\text { 水平 }(y)\end{array}$ & & & & \\
\hline \multirow{18}{*}{$\begin{array}{l}\text { 自 } \\
\text { 变 } \\
\text { 量 }\end{array}$} & 性别（ $\mathrm{D}_{11}$ ) & 男=1 女=0 & $\begin{array}{l}-0.0030 \\
(-0.0216)\end{array}$ & & \\
\hline & 年级 $\left(D_{21}\right)$ & 大一 $=1$ 其他 $=0$ & $\begin{array}{l}0.1430 \\
(0.428159)\end{array}$ & & \\
\hline & 年级（D $22 ）$ & 大二 $=1$ 其他 $=0$ & $\begin{array}{l}-0.0516 \\
(-0.1452)\end{array}$ & & \\
\hline & 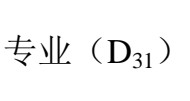 & 理学、工学 $=1$ 其他 $=0$ & $\begin{array}{l}-0.4042 \\
(-2.0794)\end{array}$ & & \\
\hline & 专业（D $32 ）$ & $\begin{array}{l}\text { 文学、哲学、历史学 } \\
=1 \text { 其他=0 }\end{array}$ & $\begin{array}{l}-0.3425 \\
(-1.5368)\end{array}$ & & \\
\hline & & 经济学、管理学=1其 & -0.2942 & -0.1728 & \\
\hline & 专业（D跑） & 他=0 & $(-1.6288)$ & $(0.1303)$ & \\
\hline & 土情 $(\mathrm{O})$ & 教育学、法学=1 其他 & -0.3270 & & \\
\hline & 专业 $\left(\mathrm{D}_{34}\right)$ & $=0$ & $(-1.3329)$ & & \\
\hline & 户口 $\left(\mathrm{D}_{41}\right)$ & 城镇=1 农村=0 & $\begin{array}{l}0.0848 \\
(0.6828)\end{array}$ & & \\
\hline & 月生活费 & & -0.0003 & -0.0003 & -0.0003 \\
\hline & $\left(X_{i}\right)$ & & $(-1.9529)$ & $(0.0001)$ & $(0.0001)$ \\
\hline & 在校干部工 & 是 $=1$ 否 $=0$ & -0.0524 & & \\
\hline & $\begin{array}{c}\text { 作经历 } \\
\left(\mathrm{D}_{5}\right)\end{array}$ & & $(-0.4417)$ & & \\
\hline & 学习成绩 & 班级前 $30 \%=1$ 其他 $=0$ & 0.6362 & 0.6045 & 0.6031 \\
\hline & $\left(D_{61}\right)$ & & $(3.2533)$ & $(0.1837)$ & $(0.1843)$ \\
\hline & 学习成绩 & 班级前 $30 \%-70 \%=1$ 其 & 0.3857 & 0.3754 & 0.3710 \\
\hline & $\left(D_{62}\right)$ & 他=0 & $(3.1605)$ & $(0.1157)$ & $(0.1159)$ \\
\hline
\end{tabular}

拟变量, $D_{4 i}$ 表示户籍, $D_{5 i}$ 表示在校干部工作经历的虚 拟变量, $D_{6 i}$ 学习成绩的虚拟变量, $X_{i}$ 表示大学生月生 活费。
剔除变量 “专业”, 然后再次进行回归。得到模型 (3) 的回归结果, 各变量均显著。

根据回归结果, $\mathrm{Y}$ (大学生信用水平) 与 $\mathrm{X}_{\mathrm{i}}$ (月生 活费）、 $\mathrm{D}_{6 \mathrm{i}}$ (学习成绩) 的估计结果为: 


$$
\begin{aligned}
& \mathrm{Y}=7.0455-0.0003 * \mathrm{X}_{\mathrm{i}} \text { 学习成绩在班级前 30\% } \\
& \mathrm{Y}=6.8133-0.0003 * \mathrm{X}_{\mathrm{i}} \text { 学习成绩在班级前 30\%-70\% } \\
& \mathrm{Y}=4.4423-0.0003 * \mathrm{X}_{\mathrm{i}} \text { 学习成绩在年级后 } 30 \%
\end{aligned}
$$

综上, 计量回归分析中部分大学生信用水平影响因 素得到验证, 其中学习成绩影响较为显著, 在其他条件 不变的情况的下, 学习成绩从后 $30 \%$ 学生成绩提高一个 段次, 信用水平的数值提高 0.3709 。月生活费每增加一 元, 学生的信用水平下降 0.0003 。（参见表 5)

\section{C. 大学生诚信信用回归分析}

以 $\mathrm{Y}_{1}$ (大学生诚信信用) 被解释变量, 对 $\mathrm{X}_{\mathrm{i}}$ (月 生活费)、 $\mathrm{D}_{6 \mathrm{i}}$ (学习成绩) 进行简单回归分析, 得回 归方程:

$\mathrm{Y}=20.3200-0.0011 * \mathrm{X}_{1}$ 学习成绩在班级前 30\% $\mathrm{Y}=19.54056-0.0011 * \mathrm{X}_{1}$ 学习成绩在班级前 30\%-70\% $\mathrm{Y}=18.2278-0.0011 * \mathrm{X}_{1}$ 学习成绩在年级后 $30 \%$

结果表明, 学习成绩对学生诚信信用影响较为显 著, 在其他条件不变的情况下, 学习成绩从后 $30 \%$ 学生 成绩提高一个段次, 信用水平的数值提高 1.2778 。（参 见表 6)

表 6 剔除部分变量回归分析结果

\begin{tabular}{ccc}
\hline 变量名称 & \multicolumn{1}{c}{ 变量定义 } & $(4)$ \\
\hline 变量 & & \\
诚信信用 & & \\
$\left(\mathrm{y}_{1}\right)$ & & \\
自变量 & & -0.0010 \\
月生活费 & & $(0.0004)$ \\
$\left(\mathrm{X}_{\mathrm{i}}\right)$ & & 2.0022 \\
学习成绩 & 班级前 $30 \%=1$ & $(0.5306)$ \\
$\left(\mathrm{D}_{61}\right)$ & 其他 $=0$ & 1.2778 \\
学习成绩 & 班级前 $30 \%-$ & $(0.3336)$ \\
$\left(\mathrm{D}_{62}\right)$ & $70 \%=1$ 其他 $=0$ & \\
\hline
\end{tabular}

\section{D. 回归分析结果总结}

从理论角度, 大学生信用建设因素是影响大学生信 用水平的重要影响因子, 根据回归结果, 大学生的学习 成绩对其信用水平有正向影响关系, 这表明学校教育对 学生的信用发展和综合素质发挥重要作用, 高校需注重 学生的信用教育, 制定大学生诚信教育的管理制度, 提 升学生整体信用水平。月生活费因素对学生信用的显著 影响表明大学生信用高低受其经济能力的影响, 分析学 生信用水平应该注重考虑学生的经济行为和经济状况。 从大学生专业因素看, 剔除相关解释变量后, 理工科专 业对大学生信用水平的显著性, 表明不同专业对大学生 信用水平有一定的影响, 学校在进行诚信教育时, 可结 合学生不同的专业特点, 采取有针对性的教育举措。

\section{V. 结论}

本文通过构建大学生信用评价指标和评价模型, 从 学习信用、校园生活信用、消费信用、就业信用四个维 度进行评价, 实证结果表明对大学生信用维度的划分具 有较好的理论价值和现实意义。面对大学生信用建设这 一束手问题, 应该综合考虑各主体因素的影响, 针对现 存问题对症下药。面对大学生信用建设缺乏法律法规和 保障制度的约束, 政府应加强立法工作, 推进信用管理 制度和信用体系的完善, 加强市场监管, 完善互联网金 融市场秩序, 重视市场征信的作用。学生个人更应注重 个人信用的保护和建设, 在互联网消费和社交中规范自 身行为, 培养个人信用意识。教育作为培养信用意识的 主要途径, 高校要加强对大学生的信用教育, 创新教育 模式, 将诚信教育内容规范化、模式化和实用化, 同时 家庭也应注重学生诚信道德教育, 与学校教育相辅相 成, 共同促进学生信用意识的提高。

\section{参考文献}

[1] 刘姿含, “基于结构方程模型的大学生信用评价研, ” D. 湖南大学, 2014.

[2] 王达山, “ “互联网+” 时代的个人信用分析与应用研究, ” J.西南 金融, vol. 2016, issue 08, pp. 24-29, 2016.

[3] 丁建福, “学生贷款制度运行机制: 政府与市场一一理论研究与实 证分析,”C. 中国教育经济学年会议, 2007.

[4] 藏学涁, 王栋旭, 张 琦: 大学生个人消费信用体系的基础性建设研 究. 商业经济. J. vol. 2019, issue02, pp.178-180, 2016. 